\title{
Los derechos de tanteo y retracto legal sobre la vivienda protegida en Andalucía
}

\section{María del Mar Caraza Cristín}

\begin{abstract}
SUMARIO: I. INTRODUCCIÓN. II. LOS DERECHOS DE TANTEO Y RETRACTO EN LA LEY 13/2005. A. Antecedentes normativos. B. Presupuesto de hecho. C. Duración de los derechos de tanteo y retracto legal. D. Órganos competentes para su ejercicio. E. Régimen de comunicaciones. F. Plazos. G. Precios. H. Obligaciones que se imponen a los Notarios y Registradores. I. Efectos del incumplimiento de las obligaciones legales. J. Sobre el ejercicio discrecional de estos derechos. III. APLICACIÓN TEMPORAL DE LOS DERECHOS DE TANTEO Y RETRACTO. A. Posibles interpretaciones sobre el grado de retroactividad de la Ley 13/2005. B. Normativa dictada en desarrollo de los artículos 12 y 13 de la Ley 13/2005. a. Instrucción de 29 de diciembre de 2005. b. Orden de 20 de enero de 2006. c. Orden de 10 de marzo de 2006. d. Decreto 149/2006, de 25 de julio de 2006. IV. ESPECIAL REFERENCIA A LA APLICACIÓN DE LA PROHIBICIÓN DE TRANSMISIÓN O CESIÓN DE USO DE LA VIVIENDA EN LAS SEGUNDAS O POSTERIORES TRANSMISIONES. V. VALORACIÓN.
\end{abstract}

\section{INTRODUCCIÓN}

La reciente entrada en vigor de la Ley 13/2005, de 11 de noviembre, de Medidas para la Vivienda Protegida y el Suelo, el 21 de diciembre de 2005, ha supuesto en materia de vivienda protegida una auténtica novedad en el panorama normativo andaluz. Es la primera vez que el legislador andaluz hace uso de la competencia exclusiva que sobre la vivienda le atribuye el artículo 13.8 de su Estatuto de Autonomía, aprobado por la Ley Orgánica 6/1981, de 30 de diciembre.

Con anterioridad a esta Ley, han sido numerosos Reales Decretos y Decretos los que de forma dispersa han ido configurando y dando cuerpo a esta vasta materia.

Ahora, la Ley 13/2005, de 11 de noviembre, procede a sistematizar y condensar en un único cuerpo legal los aspectos más importantes y trascenden- 
tales con relación al régimen jurídico de la vivienda protegida. Entre ellos, destaca la regulación que de los derechos de tanteo y retracto se contiene en los artículos 12 y 13.

El ejercicio de los citados derechos, así como la regulación procedimental que de los mismos acomete la Ley, ha suscitado desde los más diversos sectores un cúmulo de incertidumbres interpretativas, principalmente, con relación al tema de la retroactividad o no de la norma.

En parte, esta situación explica la pronta reacción de la Administración Pública andaluza en elaborar y publicar una serie de normas de desarrollo de estos preceptos legales con el propósito de ofrecer, de esta manera, la mayor seguridad jurídica al régimen de aplicación de estos derechos legales.

Ciertamente, la producción normativa en estos últimos meses ha sido abrumadora: la Ley 13/2005, de 11 de noviembre; la Instrucción de 29 de diciembre de 2005; la Orden de 20 de enero de 2006; la Orden de 10 de marzo de 2006; la Ley 1/2006, de 16 de mayo; y el Decreto 149/2006, de 25 de julio. Es por ello, que el principal objetivo que persigue el presente estudio es facilitar un cuadro del que se desprenda de la forma más clara posible cómo se aplica la regulación contenida en los artículos 12 y 13 de la Ley 13/2005 a las viviendas protegidas dependiendo del régimen jurídico al que se acojan, ofreciendo, al mismo tiempo, una visión de conjunto de la regulación de estos derechos y resaltando, especialmente, aquellos aspectos sustantivos y procedimentales más llamativos o novedosos.

\section{LOS DERECHOS DE TANTEO Y RETRACTO EN LA LEY 13/2005, DE 11 DE NOVIEMBRE, DE MEDIDAS PARA LA VI- VIENDA PROTEGIDA Y EL SUELO}

\section{A. Antecedentes normativos}

Hasta la Ley 13/2005, en la Comunidad Autónoma andaluza han regulado los derechos de tanteo y retracto de tipo convencional los Decretos reguladores de los regímenes de financiación en materia de vivienda aplicables al I y II Plan Andaluz de Vivienda y Suelo y los Decretos por los que se aprueban el III y IV Plan de Vivienda y Suelo en Andalucía ${ }^{1}$.

\footnotetext{
${ }^{1}$ Así, vid. artículo 34 del Decreto 119/1992, de 7 de julio, por el que se regula el Régimen de Financiación de las actuaciones de los Sectores Público y Protegido en materia de Vivienda, establecido en el Plan Andaluz de Vivienda 1992-1995; artículo 17 del Decreto 120/1992, de 7 de ju-
} 
Tomando como muestra el artículo 97 del IV Plan andaluz de Vivienda y Suelo $^{2}$, se observa que la ordenación de estos derechos se remite, por lo que se refiere al derecho de retracto, a lo dispuesto en los artículos 1507 y siguientes del Código $\mathrm{Civil}^{3}$.

lio, por el que se regula el Régimen de Financiación Cualificada de las actuaciones protegibles en materia de Suelo del Plan Andaluz de Vivienda 1992-1995 y el procedimiento para la declaración de las mismas por la Junta de Andalucía; los artículos 21.3 y 54 del Real Decreto 2190/1995, de 28 de diciembre, sobre medidas de financiación de actuaciones protegibles en materia de vivienda y suelo para el periodo 1996-1999; artículos 41, 49 y 59 del Decreto 166/1999, de 27 de julio, por el que se regulan las actuaciones contenidas en el III Plan andaluz de Vivienda y Suelo 19992002; artículos 29 y 96 del Decreto 149/2003, de 10 de junio, por el que se aprueba el IV Plan Andaluz de Vivienda y Suelo en Andalucía 2003-2007 y se regulan las actuaciones contempladas en el mismo y el artículo 97 de la Orden de 8 de agosto de 2005, por la que se publica el Texto Integrado del Decreto 149/2003, de 10 de junio, por el que se aprueba el Plan Andaluz de Vivienda y Suelo 2003-2007, y se regulan las actuaciones contempladas en el mismo, con las modificaciones introducidas por el Decreto 463/2004, de 25 de julio, y el Decreto 180/2005, de 26 de julio.

${ }^{2}$ El artículo 97 de la Orden de 8 de agosto de 2005 dispone en relación con los derechos de tanteo y retracto lo siguiente:

"1. El promotor de actuaciones de viviendas protegidas tendrá la obligación de pactar expresamente con los adjudicatarios de las mismas los derechos de tanteo y retracto sobre las viviendas, a favor de la Empresa Pública de Suelo de Andalucía o de otras Entidades o Empresas Municipales de Vivienda que aquélla designe, con una vigencia de diez años, debiendo inscribirse en el Registro de la Propiedad.

Estos derechos se ejercerán de conformidad con lo establecido en los arts. 1507 y ss. del Código Civil, y con arreglo a lo dispuesto en el presente artículo, a cuyos efectos se harán constar el ejercicio de los mismos en los contratos y escrituras de dichas viviendas.

2. Los propietarios cuyas viviendas estén sujetas al derecho de tanteo y retracto previsto en el apartado anterior, deberán notificar al beneficiario del derecho la decisión de enajenarlas, con expresión del precio y forma de pago proyectados y restantes condiciones esenciales de la transmisión, a efectos del ejercicio del derecho de tanteo, durante un plazo de sesenta días naturales a contar desde el siguiente al que se haya producido la notificación.

3. El beneficiario podrá ejercitar el derecho de retracto cuando no se le hubiere hecho la notificación prevista en el apartado 2 de este artículo, se omitiese en ella cualquiera de los requisitos exigidos o el precio efectivo de la transmisión resultara inferior o menos onerosas las restantes condiciones de las mismas.

Este derecho deberá ejercitarse en el plazo de sesenta días naturales a contar desde que el beneficiario tenga constancia de la transmisión de la vivienda".

${ }^{3}$ El Código Civil regula en las Secciones Primera y Segunda del Capítulo VI del Título IV del Libro IV los derechos de retracto convencional y legal. De acuerdo con el artículo 1507 del Código Civil, el retracto convencional tendrá lugar cuando el vendedor se reserve el derecho de recuperar la cosa vendida, estando obligado en tal caso a rembolsar al comprador el precio de la venta, los gastos del contrato, cualquier otro pago legítimo hecho para la venta, así como los gastos necesarios y útiles hechos en la cosa vendida. Este derecho durará, a falta de pacto expre- 
En el Derecho autonómico comparado sí encontramos, en cambio, diversas leyes autonómicas en materia de vivienda que regulan estos derechos de tanteo y retracto, así, los artículos: 29.4 de la Ley aragonesa 24/2003, de 26 de diciembre; 65.2 de la Ley canaria 2/2003, de 30 de enero; 52 de la Ley de Castilla-La Mancha, de 7 de febrero de 2002; 49.2 de la Ley extremeña 3/2001, de 26 de abril; 52.3 de la Ley valenciana 8/2004, de 20 de octubre; y 31.1 de la Ley Foral de Navarra 8/2004, de 24 de junio.

\section{B. Presupuesto de hecho}

En primer lugar, el ejercicio de los derechos ${ }^{4}$ de tanteo y retracto requiere que se trate de una vivienda protegida, esto es, aquella que cumpla con las condiciones de uso, destino, calidad $^{5}$, precio de venta o alquiler y, en su caso, superficie y diseño, establecidas en la Ley 13/2005 y en las demás disposiciones que resulten de aplicación y que haya sido calificada como tal por la Consejería competente en materia de vivienda, en la actualidad, la Consejería de Obras Públicas y Transportes ${ }^{6}$.

Asimismo, de acuerdo con el párrafo segundo del artículo 2 de la citada Ley, también tendrán dicha consideración los alojamientos que, de cuerdo con lo establecido reglamentariamente, sean calificados como protegidos por la referida Consejería.

so, cuatro años contados desde la fecha del contrato. En el caso de que exista una estipulación al respecto, el plazo no podrá exceder de diez años, según dispone el artículo 1508 del Código Civil. Por su parte, el artículo 1521 define el retracto legal como el derecho de subrogarse, con las mismas condiciones estipuladas en el contrato, en el lugar del que adquiere una cosa por compra o dación en pago.

\footnotetext{
${ }^{4}$ Sobre la interesante cuestión de la verdadera naturaleza de estos tanteos y retractos, como facultades o potestades administrativas de intervención en vez de derechos, manifiesta José Ignacio MORILLO-VELARDE PÉREZ que su razón de ser es proporcionar a la Administración competente un instrumento jurídico para la consecución de los objetivos concretos que asigna la legislación sectorial, vid. "Los Retractos Legales a favor de las Administraciones Públicas", Revista de Administración Pública núm. 165 (septiembre-diciembre 2004), págs. 72-76 y 83-84.

${ }^{5}$ Precisamente, en estos momentos se está tramitando un borrador de Ley de Calidad de la Vivienda en Andalucía, cuyas prescripciones también serán, evidentemente, de aplicación a las viviendas protegidas.

${ }^{6}$ En relación con el concepto legal de vivienda de protección oficial vid. Felipe IGLESIAS GONZÁLEZ, Régimen Jurídico de la Protección a la Promoción y Adquisición de Viviendas, Aranzadi, Navarra, 2000, págs. 71-124.
} 
En consecuencia, estos derechos no pueden ejercitarse cuando se trate de viviendas libres, esto es, no calificadas como protegidas. Incluso en el supuesto de que la vivienda sea de renta tasada, por estar acogida a algún régimen de financiación, la misma sigue siendo libre, por lo que no le afectan las medidas reguladas en esta Ley ${ }^{7}$.

Y en segundo lugar, se ha de tratar de la segunda o posterior transmisión del derecho de propiedad o de cualquier otro derecho de uso y disfrute sobre la vivienda protegida ${ }^{8}$.

Aunque, en principio, el apartado primero del artículo 12 habla de segundas y posteriores transmisiones, término amplio que abarcaría a supuestos de compraventa y donación ${ }^{9}$, empero, el apartado segundo de este mismo artículo se refiere a que el titular de la vivienda habrá de comunicarle a la Administración "el precio y la forma de pago" y el apartado tercero habla de que la persona adquirente ha de comunicar al órgano competente las condiciones en que se ha producido "la venta", con lo cual se excluirían los supuestos de transmisiones gratuitas como la donación. En definitiva, parece que, en realidad, el supuesto de transmisión en el que está pensando el legislador es la compraventa ${ }^{10}$.

\footnotetext{
${ }^{7}$ Sobre las antiguas viviendas de precio tasado y su calificación o no como vivienda de protección oficial vid. Miguel BELTRÁN DE FELIPE, La intervención administrativa en la vivienda. Aspectos competenciales, de policía y de financiación de las viviendas de protección oficial, Lex Nova, Valladolid, 2000, págs. 115 y 116.

${ }^{8}$ En otras Leyes autonómicas en materia de vivienda se concreta algo más la redacción de esta cuestión. En este sentido, los artículos 51.1 de la Ley valenciana 8/2004, de 20 de octubre y 35.1 de la Ley gallega 4/2003, de 29 de julio, establecen que la Administración autonómica en cuestión ostentará estos derechos sobre las viviendas y sus anejos en las segundas y sucesivas transmisiones inter vivos, sean éstas gratuitas u onerosas, voluntarias o como consecuencia de un procedimiento de ejecución patrimonial.

${ }^{9}$ Comenta José Ángel BLANCO BAREA, al hilo del análisis y comentario del artículo 10 del Real Decreto 1/2002, que el tipo de transmisiones de la propiedad a la que se refiere dicho artículo se limita expresamente a los actos inter vivos, "permitiendo, con buena lógica, que las transmisiones mortis causa no se encuentren, no ya limitadas (que podrían, mediante un derecho de retracto ante las Administraciones autonómica o local cuando son éstas las vendedoras), sino no sometidas a imposiciones de ninguna especie, por ello no se penaliza con obligación de devolución de ayudas el supuesto de transmisión por vía testamentaria, ya lo sea a título de heredero o legatario, o intestada para los casos de herederos exclusivamente (que parecería, en cualquier caso, excesivo", vid. Viviendas de protección pública (VPO). Tramitación administrativa y ayudas. Normativa estatal y autonómica, Comares, Granada, 2004, págs. 216-224.
}

${ }^{10}$ En este sentido se posiciona Joaquín ZEJALBO MARTÍN cuando afirma que el ejercicio de estos derechos "solo puede tener lugar en el supuesto de compraventa: el artículo 12 de la Ley, 
En particular, con relación al derecho de retracto, se requiere que concurra además alguna de estas circunstancias: que en el caso de quienes transmitan o adquieran no hubieran realizado las comunicaciones a que se refiere el apartado 2 del artículo 12 de la Ley, que las comunicaciones fueran incompletas o defectuosas, o que las transmisiones se hayan realizado antes del transcurso del plazo de los sesenta días para el ejercicio del derecho de tanteo o en condiciones distintas a las anunciadas.

\section{Duración de los derechos de tanteo y retracto legal}

A diferencia de los derechos de tanteo y retracto convencionales que han venido regulándose en los diferentes Planes andaluces de Vivienda y Suelo, cuya vigencia era de diez años, el legislador andaluz ha optado porque la vigencia de los derechos de tanteo y retracto legal se extienda a todo el periodo de protección de la vivienda protegida ${ }^{11}$. Aunque el art. 12 no lo dice expresamente, se entiende implícita dicha interpretación ${ }^{12}$.

Así, pues, la duración de los derechos de tanteo y retracto configurados por la Ley andaluza se corresponde con el periodo de protección de la vivienda. Por lo tanto, habrá que estar a los correspondientes Reales Decretos reguladores de los Planes de Vivienda estatales y los Decretos reguladores de los Planes andaluces de Vivienda y Suelo para determinarlo.

Atendiendo a las viviendas que a fecha de 2006 se encuentran calificadas como protegidas, se pueden distinguir los siguientes periodos de protección:

nos habla del precio de la transmisión y de las condiciones en las que se ha producido la venta. Por supuesto, quedan excluidas las aportaciones a la sociedad ganancial, las adjudicaciones derivadas de la liquidación de la sociedad ganancial, las permutas, la cesión de vivienda a cambio de alimentos, la extinción de comunidad y, en general, toda transmisión onerosa que no sea mediante compraventa", vid. "La doctrina sobre la retroactividad y la aplicación inmediata de la Ley a propósito de la Ley andaluza sobre vivienda protegida y cuestiones prácticas", de 18 de enero de 2006, en BOE para Notarías, Registros y Sociedades, en http://www.notariosyregistradores.com/doctrina/ARTICULOS, pág. 6 de 7.

${ }^{11}$ Hay, sin embargo, otras Leyes autonómicas que han optado por mantener una vigencia temporal de diez años para el ejercicio de los derechos de tanteo y retracto legal en materia de vivienda, así, vid. los arts. 51.3 de la Ley valenciana 8/2004, de 20 de octubre, y 35.3 de la Ley gallega 4/2003, de 29 de julio.

${ }^{12}$ En cambio, otras Leyes autonómicas sí lo explicitan, así, el art. 29.1 de la Ley aragonesa $24 / 2003$, de 26 de diciembre, dispone que el derecho de tanteo sobre viviendas protegidas de promoción privada lo ejercerá la Administración en tanto se mantenga el régimen de protección. 
- 50 años de protección para las viviendas acogidas al Real Decreto 2960/1976, de 12 de noviembre, Texto Refundido de Vivienda de Protección Oficial ${ }^{13}$.

- 30 años de protección para las viviendas acogidas al Real Decreto Ley $31 / 1978$, de 31 de octubre ${ }^{14}$.

- 30 años para las viviendas acogidas a la regulación del I, II y III Plan Andaluz de Vivienda y Suelo para los periodos $1992-1995^{15}, 1996-$ $1999^{16}$ y $1999-2002^{17}$, respectivamente.

\footnotetext{
${ }^{13}$ Hay que subrayar que aunque las viviendas acogidas a este Real Decreto siguen siendo calificadas como protegidas, su precio de venta es libre, de acuerdo con lo dispuesto en el Real Decreto $727 / 1993$, de 14 de mayo, que dispone que el precio de venta en segunda y posteriores transmisiones de las viviendas de protección oficial de promoción privada acogidas a regímenes anteriores al Real Decreto-Ley 31/1978, de 31 de octubre, será el que libremente acuerden las partes.
}

14 Téngase en cuenta la regulación contenida en los siguientes Reales Decretos: 3148/1978, de 10 de noviembre; 1494/1987, de 4 de diciembre, sobre medidas de financiación de actuaciones protegibles en materia de Vivienda; y 224/1989, de 3 de marzo, sobre medidas de financiación de actuaciones protegibles en materia de Vivienda.

${ }^{15}$ Respecto a las viviendas acogidas al periodo que comprendería el I Plan Andaluz de Vivienda y Suelo, téngase en cuenta la siguiente normativa: el Real Decreto 1932/1991, de 20 de diciembre, sobre medidas de financiación de actuaciones protegibles en materia de vivienda del Plan 1992-1995; el Real Decreto 726/1993, de 14 de mayo, por el que se regula la financiación de actuaciones protegibles en materia de rehabilitación de inmuebles y se modifican determinados artículos del Real Decreto 1932/1991, de 20 de diciembre; el Decreto 119/1992, de 7 de julio, por el que se regula el Régimen de Financiación de las actuaciones de los Sectores Público y Protegido en materia de Vivienda, establecido en Plan Andaluz de Vivienda 1992/1995; el Decreto 120/1992, de 7 de julio, por el que se regula el Régimen de Financiación Cualificada de las actuaciones protegibles en materia de Suelo del Plan Andaluz de Vivienda 1992/1995 y el procedimiento para la declaración de las mismas por la Junta de Andalucía; el Decreto 13/1995, de 31 de enero, por el que se establecen medidas para facilitar el acceso de los jóvenes a la vivienda; y el Real Decreto 2028/1995, de 22 de diciembre, por el que se establecen las condiciones de acceso a la financiación cualificada estatal de viviendas de protección oficial promovidas por cooperativas y comunidades de propietarios al amparo de los planes estatales de vivienda.

${ }^{16}$ Respecto a las viviendas acogidas al periodo que comprendería el II Plan Andaluz de Vivienda y Suelo, téngase en cuenta la siguiente normativa: el Real Decreto 2190/1995, de 28 de diciembre, sobre medidas de financiación de actuaciones protegibles en materia de vivienda y suelo para el período 1996-1999; el Real Decreto 1/1997, de 10 de enero, por el que se modifica parcialmente el Real Decreto 2190/1995, de 28 de diciembre, sobre medidas de financiación de actuaciones protegibles en materia de vivienda y suelo para el período 1996-1999; el Decreto 
- 30 años para las viviendas acogidas a la regulación del IV Plan Andaluz de Vivienda y Suelo para el periodo 2003-2007, salvo que se trate de viviendas de iniciativa municipal y autonómica, en cuyo caso, el plazo de protección concluirá al transcurrir el periodo establecido para la amortización del préstamo cualificado. Cuando se trate de préstamos a 10 años, o de no existir préstamo, el período será de 15 años. Y en el supuesto de amortización anticipada de préstamos a 25 años el período de protección no será inferior a 15 años ${ }^{18}$.

51/1996, de 6 de febrero, por el que se regulan las actuaciones contenidas en el II Plan Andaluz de Vivienda y Suelo 1996-1999; el Real Decreto 1377/1996, de 7 de junio, de medidas económicas de liberalización (modifica parcialmente el Real Decreto 2190/1996); y el Decreto 357/1996, de 16 de julio por el que se modifica el Decreto 51/1996, de 6 de febrero, por el que se regulan las actuaciones contenidas en el II Plan Andaluz de Vivienda y Suelo 1996-1999, y se contemplan determinadas situaciones de transitoriedad referidas a las viviendas a precio tasado.

${ }^{17}$ Respecto a las viviendas acogidas al periodo que comprendería el III Plan Andaluz de Vivienda y Suelo, téngase en cuenta la siguiente normativa: el Real Decreto 1186/1998, de 12 de junio, sobre medidas de financiación de actuaciones protegibles en materia de vivienda y suelo del Plan 1998-2001; el Decreto 251/1998, de 10 de diciembre, por el que se regula el Régimen de Ayudas Económicas y Financieras de actuaciones protegibles en materia de vivienda y suelo al amparo del Real Decreto 1186/1998, de 12 de junio, sobre Medidas de financiación en materia de vivienda y suelo del Plan 1998-2002; el Decreto 166/1999, de 27 de julio, por el que regulan las actuaciones contenidas en el III Plan Andaluz de Vivienda y Suelo 1999-2002; el Real Decreto 115/2001, de 9 de febrero, por el que se modifica el Real Decreto 1186/1998, de 12 de junio, sobre medidas de financiación de actuaciones protegibles en materia de vivienda y suelo del Plan 1998-2001, y se establece la ayuda estatal directa a la entrada; el Decreto 56/2001, de 26 de febrero, por el que se adapta la normativa autonómica en materia de vivienda a lo establecido en el Real Decreto 115/2000, de 23 de junio; el Decreto 145/2001, de 19 de junio, por el que se adoptan medidas específicas en relación con los programas autonómicos de vivienda y se modifica el Decreto 166/1999, de 27 de julio, por el que se regulan las actuaciones contenidas en el III Plan Andaluz de Vivienda y Suelo 1999-2002; el Real Decreto 1/2002, de 11 de enero, sobre medidas de financiación de actuaciones protegidas en materia de vivienda y suelo del Plan 2002-2005; y el Decreto 127/2002, de 17 de abril, por el que se modifica la normativa del III Plan Andaluz de Vivienda y Suelo 1999-2002 y se establecen medidas específicas en relación con los programas regulados en el mismo.

${ }^{18}$ La normativa a tener en cuenta en relación con el IV Plan Andaluz de Vivienda y Suelo viene dada por: el Real Decreto 1/2002, de 11 de enero, sobre medidas de financiación de actuaciones protegidas en materia de vivienda y suelo del Plan 2002-2005; el Decreto 149/2003, de 10 de junio, por el que se aprueba el IV Plan Andaluz de Vivienda y Suelo en Andalucía 2003-2007 y se regulan las actuaciones contempladas en el mismo; el Real Decreto 1042/2003, de 1 de agosto, por el que se modifica el Real Decreto 1/2002, de 11 de enero, sobre medidas de financiación de actuaciones protegidas en materia de vivienda y suelo del Plan 2002-2005, y se crean los municipios singulares del grupo 0 a efectos de adquisición protegida de viviendas; el Real Decreto 1721/2004, de 23 de julio, por el que se modifica el Real Decreto 1/2002, de 11 de enero, sobre 
No obstante lo expuesto, hay que advertir que, en la práctica, el plazo para ejercitar estos derechos quedará reducido a un periodo de diez años, o incluso menos, atendiendo a la regulación que de la descalificación de las viviendas protegidas ha hecho el Decreto 149/2006, de 25 de julio, por el que se aprueba el Reglamento de Viviendas Protegidas de la Comunidad Autónoma de Andalucía y se desarrollan determinadas disposiciones de la Ley $13 / 2005$, de 11 de noviembre ${ }^{19}$.

\section{D. Órganos competentes para su ejercicio}

El párrafo primero del apartado primero del artículo 12 establece que tanto el derecho de tanteo como el de retracto legal se ejercitarán a favor de la Administración de la Junta de Andalucía, o del Ayuntamiento o entidad pública que sean designados por aquélla.

De acuerdo con el artículo 2 de la Orden de 1 de junio de 2001, de delegación de competencias en materia de vivienda en diversos órganos de la Consejería de Obras Públicas y Transportes de la Junta de Andalucía (publicada en el BOJA número 69, de 19 de junio de 2001), los órganos competentes para ejercer el derecho de tanteo, así como la tramitación de los expedientes de ejercicio del derecho de retracto, sobre viviendas y locales comerciales de protección oficial de promoción pública o privada son los titulares de las Delegaciones Provinciales de la mentada Consejería. En los casos de ausencia, vacante o enfermedad de estos órganos, la delegación de competencias se entenderá realizada en los Secretarios Generales de las respectivas Delegaciones Provinciales.

Pues bien, de conformidad con lo dispuesto en el artículo 12.1 de la Ley, la Administración de la Junta de Andalucía podrá delegar, como hasta ahora

medidas de financiación de actuaciones protegidas en materia de vivienda y suelo del Plan 20022005, y se crean nuevas líneas de actuaciones protegidas para fomentar el arrendamiento de viviendas; el Decreto 463/2004, de 27 de julio, por el que se modifica el Decreto 149/2003; el Decreto 180/2005, de 26 de julio, por el que se modifica el Decreto 149/2003; la Orden de 8 de agosto de 2005, por la que se publica el Texto Integrado del Decreto 149/2003, con las modificaciones introducidas por los Decretos 463/2004 y 180/2005; y el Real Decreto 801/2005, de 1 de julio, por el que se aprueba el Plan Estatal 2005-2008, para favorecer el acceso de los ciudadanos a la vivienda.

${ }^{19}$ Vid. la Disposición Transitoria Segunda (Descalificaciones de viviendas protegidas adquiridas, adjudicadas o construidas para uso propio con anterioridad a este Decreto) y el artículo 44 (Descalificación de las viviendas protegidas) del Decreto 149/2006, de 25 de julio. 
ha venido haciendo con los derechos de tanteo y retracto de tipo convencional, el ejercicio de estos derechos a favor de la Empresa Pública del Suelo de Andalucía (entidad pública dependiente de la citada Consejería cuyos Estatutos fueron aprobados por el Decreto 113/1991, de 21 de mayo, modificado por el Decreto 459/2004, de 20 de julio). De hecho, así se ha recogido finalmente en los artículos 3 de la Orden de 20 de enero de 2006, 47 de la Orden de 10 de marzo de 2006 y 50 del Reglamento de Viviendas Protegidas en la Comunidad Autónoma de Andalucía, aprobado por el Decreto 149/2006, de 25 de julio.

Por último, hay que señalar que en el último precepto citado, el párrafo segundo del apartado 2 del artículo 50 del Reglamento de Viviendas Protegidas, recoge la posibilidad de que previa solicitud del Ayuntamiento del municipio en el que se ubiquen las viviendas a la Delegación Provincial correspondiente, y una vez suscrito el correspondiente acuerdo entre ambas Administraciones, se podrá ceder el ejercicio de estos derechos a favor del Ayuntamiento o entidad pública que designe la Administración de la Junta de Andalucía.

\section{E. Régimen de comunicaciones}

Previamente a que se proceda a la transmisión de una vivienda protegida, la persona titular de la misma está obligada a comunicar al órgano competente de la Administración, esto es, al Delegado Provincial de la Consejería de Obras Públicas, los siguientes aspectos: la decisión de transmitir, el precio, la forma de pago y las demás condiciones de la transmisión.

Estos datos se materializan con la presentación de la siguiente documentación ${ }^{20}$ : aportación del DNI, u otro documento que acredite la personalidad, y fotocopia para su cotejo; una copia simple de la escritura de adquisición y datos registrales de la finca; nota simple informativa del Registro de la Propiedad con fecha anterior en no más de un mes al momento de la presente comunicación; y la comunicación de la persona interesada en la adquisición ${ }^{21}$.

\footnotetext{
${ }^{20}$ Sobre la documentación que debe aportarse vid. el artículo 28.2 del Decreto 149/2006, por el que se aprueba el Reglamento de Vivienda Protegida, y la información contenida en la página web de la Consejería de Obras Públicas y Transportes de la Junta de Andalucía.

21 Joaquín ZEJALBO MARTÍN entiende que estas comunicaciones no deberán ser firmadas sólo por el propietario de la vivienda sino también por aquellas personas que puedan ostentar un derecho sobre la vivienda protegida, como es el caso del cónyuge consorte, el cual también de-
} 
Por su parte, el apartado segundo del artículo 12 le impone a la persona interesada en la adquisición el deber de comunicar al citado órgano los siguientes extremos: sus datos o ingresos económicos anuales, así como los del resto de los miembros integrantes de su unidad familiar.

En concreto, tendrá que presentar en la Delegación Provincial correspondiente la siguiente documentación: el DNI, u otro documento que acredite la personalidad, y fotocopia para su cotejo; copia compulsada de la declaración del IRPF de los miembros de la unidad familiar o, cuando no estuviera obligado, declaración responsable de los ingresos de la unidad familiar correspondiente al último ejercicio vencido; una declaración responsable de destinar la vivienda a residencia habitual y permanente; una declaración responsable de no tener otra vivienda en propiedad, protegida o libre, ni estar en posesión de un derecho real de uso o disfrute vitalicio conforme a lo establecido en el artículo 93 del Texto Integrado del Decreto 149/2003, de 10 de junio; la autorización a la Delegación Provincial para que ésta pueda solicitar información de carácter tributario, económico y registral o catastral sobre la titularidad de otras viviendas; y en caso de que se trate de familia numerosa o algún miembro presente minusvalías, presentación de la documentación que lo acredite ${ }^{22}$.

Al margen de estas comunicaciones, hay que tener en cuenta que, en determinadas situaciones, antes de realizar las comunicaciones descritas, será necesario haber obtenido de la Administración una autorización para la venta de la vivienda, de conformidad con lo preceptuado en los correspondientes Reales Decretos sobre medidas de financiación de actuaciones protegidas en materia de vivienda y suelo ${ }^{23}$ y los artículos 27 y 95 de la Orden de 8 de agosto de

berá firmar dicho documento, de conformidad con lo dispuesto en el artículo 1320 del Código Civil, vid. "La doctrina sobre la retroactividad y la aplicación inmediata de la Ley a propósito de la Ley andaluza sobre Vivienda Protegida y cuestiones prácticas", ob. cit., pág. 7 de 7 .

${ }^{22}$ Sobre la documentación que debe aportarse vid. el artículo 47 de la Orden de 10 de marzo de 2006, el artículo 28.3 del Decreto 149/2006, por el que se aprueba el Reglamento de Vivienda Protegida, y la información contenida en la página web de la Consejería de Obras Públicas y Transportes de la Junta de Andalucía.

${ }^{23}$ De acuerdo con el Real Decreto 1186/1998, de 12 de junio, existía una prohibición de venta de la vivienda en los 5 primeros años, salvo por causas justificadas, por razones de movilidad laboral, aumento de familia, u otra causa justificada. Luego el Real Decreto 115/2001, de 9 de febrero, por el que se modifica el Real Decreto 1186/1998, de 12 de junio, sobre medidas de financiación de actuaciones protegibles en materia de vivienda y suelo del Plan 1998-2001, y se establece la ayuda estatal directa a la entrada, amplió el periodo a 10 años. Idéntica limitación se contiene en el Real Decreto 1/2002, de 11 de enero, sobre medidas de financiación de actuacio- 
2005 por la que se publica el Texto Integrado del Decreto 149/2003 y 46 de la Orden de 10 de marzo de 2006, de desarrollo y tramitación de las actuaciones en materia de vivienda y suelo del Plan Andaluz de Vivienda y Suelo 20032007.

\section{F. Plazos}

De acuerdo con el artículo 12 de la Ley, a partir de que se haya efectuado la última de las comunicaciones anteriormente expuestas ${ }^{24}$, la Administración cuenta con un plazo de sesenta días naturales para ejercitar el derecho de tanteo. Con posterioridad, el artículo 51 del Reglamento de Viviendas Protegidas en la Comunidad Autónoma de Andalucía, de 25 de julio de 2006, ha venido a concretar el dies a quo en el que se podrá ejercitar el derecho de tanteo, indicando que será a partir del siguiente día a aquél en que se haya producido la resolución favorable a la que se refiere el artículo 28.5 del mismo, en la que se declare que procede el citado derecho, y siempre dentro del plazo de los mentados sesenta días.

En el supuesto de que transcurra el plazo de los sesenta días sin que se haya ejercitado el tanteo, podrá llevarse a efecto la transmisión en los términos fijados en las comunicaciones realizadas.

Pues bien, una vez efectuadas las comunicaciones, la persona titular de la Delegación Provincial acordará: bien tener por efectuadas las comunicaciones, resolviendo sobre si procede o no el ejercicio del tanteo y, en el primer supuesto, sobre su cesión a la Empresa Pública del Suelo de Andalucía; bien requerir al comunicante, si la documentación presentada fuese incompleta, para que en el plazo de diez días, subsane o complete la documentación; o comunicar a los interesados la no procedencia de la transmisión si no se cumplen los requisitos establecidos.

nes protegidas en materia de vivienda y suelo del Plan 2002-2005 y el Real Decreto 801/2005, de 1 de julio, por el que se aprueba el Plan Estatal 2005-2008, para favorecer el acceso de los ciudadanos a la vivienda.

24 Sobre este extremo hay que apuntar que la Ley habla de la última de las comunicaciones, por lo tanto, podrían ser simultáneas en el tiempo o sucesivas. Empero, entre la documentación que ha de aportar el titular de la vivienda protegida cuando le comunica a la Administración su intención de vender se ha incluido la aportación de la comunicación del futuro comprador, vid. www.copt.junta-andalucia.es. 
Una vez efectuada la transmisión, el adquirente de la vivienda tiene el deber de comunicar a la Delegación Provincial de la Consejería de Obras Públicas y Transportes en el plazo de los treinta días naturales siguientes a aquélla las condiciones en las que se ha realizado la venta. Igualmente, deberá aportar una copia de la escritura o el documento donde se haya formalizado la venta.

Cuando quienes transmitan o adquieran no hubieran realizado las comunicaciones descritas, o cuando éstas fueran incompletas o defectuosas, o cuando la transmisión se haya efectuado antes de que hayan transcurrido los sesenta días con que cuenta la Administración para hacer uso del derecho de tanteo, o la transmisión se haya llevado a cabo en condiciones distintas a las anunciadas, el órgano competente podrá ejercer el derecho de retracto en el plazo de sesenta días naturales a contar desde el siguiente a la comunicación de la transmisión, o de que ésta haya llegado a su conocimiento.

\section{G. Precios}

El derecho de tanteo se ejercerá, según reza el artículo 51 del Reglamento de Viviendas Protegidas de 2006, por el precio que hubiese señalado el transmitente en su comunicación, que ha de estar comprendido dentro del precio máximo al que se refiere el artículo $27^{25}$ del mismo. Asimismo, dicho precio máximo será el que se tome en las transmisiones inter vivos en las que no medie precio.

\footnotetext{
${ }^{25}$ El artículo 27 del Reglamento de Viviendas Protegidas en la Comunidad Autónoma de Andalucía, aprobado por el Decreto 149/2006, de 25 de julio, dispone que:

"El precio de venta de las viviendas protegidas en segundas o posteriores transmisiones será el que las partes libremente acuerden que, en ningún caso, podrá superar el mayor de los precios siguientes:

El de venta de la vivienda protegida de nueva construcción en el momento de la transmisión, correspondiente a un programa asimilable.

El de la primera transmisión, actualizado en la forma que fije el correspondiente plan de vivienda, con aplicación, en su caso, de los coeficientes correctores que establezca.

Transcurridos quince años desde la fecha de la calificación definitiva, el precio límite a tener en cuenta será, si este fuera superior, el de las viviendas correspondientes al Programa de Viviendas de Iniciativa Municipal y Autonómica o programa asimilable que contemple un precio máximo superior para la primera transmisión de las viviendas.

Si la vivienda protegida hubiera aumentado su superficie, de conformidad con lo establecido en el artículo 25.2, el precio máximo de venta se computará sobre la nueva superficie.

Si la vivienda hubiese experimentado mejoras que por su naturaleza puedan significar un aumento del valor de la misma, el precio de venta fijado por las partes, dentro de los límites previstos en este artículo, se podrá incrementar por un importe máximo del 10 por ciento”.
} 
Por su parte, el precio por el que se ejercerá el derecho de retracto será, de acuerdo con el artículo 52 del Reglamento, el de transmisión que figure en la escritura o contrato de adquisición que, en todo caso, no podrá exceder el precio establecido en el citado artículo 27 del Decreto que será, igualmente, el que se asuma en el caso de las transmisiones inter vivos en las que no figure precio.

Por último, hay que señalar que el apartado cuarto del citado artículo 52 aclara que el órgano que haya ejercitado el derecho de retracto también habrá de abonar al adquirente retraído la cuota del Impuesto sobre Transmisiones Patrimoniales y Actos Jurídicos Documentados que éste hubiera satisfecho. En cambio, no tendrá que abonarle la cuota del Impuesto sobre el Incremento de Valor de los Terrenos de Naturaleza Urbana, aunque se haya obligado a pagarlo.

\section{H. Obligaciones que se imponen a los Notarios y Registradores}

En cuanto a los Notarios y a los Registradores, el apartado quinto del artículo 12 les impone que los derechos de tanteo y retracto legal consten expresamente en la correspondiente escritura pública y tengan su reflejo en la respectiva inscripción registral.

En particular, respecto a los Notarios la Ley les obliga a:

En primer lugar, para poder elevar a escritura pública la transmisión, han de exigir al transmitente y al adquirente de la vivienda protegida que acrediten el cumplimiento de las comunicaciones antes descritas, así como que ha vencido el plazo de los sesenta días para el ejercicio del derecho de tanteo, circunstancias éstas que han de testimoniar en las correspondientes escrituras.

Y en segundo lugar, deben de comunicar a la Consejería de Obras Públicas y Transportes la transmisión mediante la remisión de copia simple de la escritura pública en la que se hubiera instrumentado la venta de la vivienda.

Y respecto a los Registradores, el apartado tercero del art. 13 de la Ley establece que para inscribir en el Registro de la Propiedad las transmisiones efectuadas sobre las viviendas protegidas debe acreditarse el cumplimiento de los requisitos antes señalados, esto es, la realización de las comunicaciones, el transcurso del plazo de los sesenta días y el reflejo de dichas circunstancias en la correspondiente escritura. 
Por otra parte, hay que indicar que el artículo 5.1 del Decreto 149/2006, de 25 de julio, añade a la obligación de los Notarios de poner en conocimiento de la Consejería de Obras Públicas y Transportes el otorgamiento de cualesquiera escrituras en las que se instrumenten la primera o posteriores transmisiones del derecho de propiedad o de cualquier otro derecho real de uso y disfrute, la de comunicar los contratos de arrendamiento y el otorgamiento de escrituras de declaración de obra nueva en el caso del promotor individual para uso propio.

Se prevé que la práctica de estas comunicaciones pueda realizarse por vía telemática, previo Acuerdo formalizado entre la Consejería de Obras Públicas y Transportes, el Consejo General del Notariado y los Colegios Notariales andaluces. Los detalles y características técnicas de este medio de comunicación electrónica serán fijados en el referido Acuerdo, según se dispone en el apartado tercero del artículo 5 del Decreto.

\section{Efectos del incumplimiento de las obligaciones legales}

De acuerdo con el apartado cuarto del artículo 13 de la Ley, las transmisiones de viviendas protegidas en las que las partes no hayan realizado las comunicaciones, en la forma y plazos previstos en el artículo 12 de la misma, serán nulas de pleno derecho.

Asimismo, se considera infracción grave de acuerdo con la letra a) del artículo 19 "el incumplimiento, por quienes promuevan o tengan las viviendas en propiedad, de la obligación de hacer constar en la escritura pública las prohibiciones y limitaciones a la facultad de disponer resultantes de actuaciones protegidas". Por su parte, el artículo 20 califica en su letra k) como infracción muy grave "la falta de comunicación a la Administración de la enajenación de la vivienda protegida a los efectos de ejercicio de los derechos de adquisición preferente, tanteo, retracto u otra facultad análoga sobre viviendas protegidas previstas en las normas de aplicación ${ }^{26 ”}$.

Y por último, con base en el art. 14.1.e) de la Ley, existirá causa de utilidad pública o interés social a los efectos de la expropiación forzosa por in-

\footnotetext{
${ }^{26}$ Las sanciones que se contemplan en el art. 21 de la Ley 13/2005 son de tipo económico, esto es, consisten en multas que oscilan entre los 3.001 y los 30.000 euros para las infracciones graves, y los 30.001 hasta los 120.000 euros para las muy graves. Estas cantidades serán actualizadas por el Consejo de Gobierno, según dispone la Disposición final tercera de la Ley.
} 
cumplimiento de la función social de la propiedad de las viviendas protegidas cuando se incumplan las obligaciones, condiciones y requisitos establecidos para la enajenación en primera o posteriores transmisiones.

\section{J. Sobre el ejercicio discrecional de estos derechos}

Cabe plantearse si puede la Administración ejercer los derechos de tanteo y retracto aún cuando se hayan respetado por parte del vendedor y del comprador todas las obligaciones que les impone la Ley, no se sobrepase el precio máximo de venta y los ingresos del comprador no excedan de los estipulados normativamente.

Sobre este particular, se ha mantenido ${ }^{27}$ que en este caso la Administración no podría ejercitar los derechos de tanteo y retracto por carecer de los motivos objetivos para ello y que, si lo hiciera, su ejercicio sería arbitrario, prohibido por la Constitución, de conformidad con el artículo 103 y, además, una expropiación de derecho sin causa para ello.

Por contra, desde nuestro punto de vista, el posible ejercicio de estos derechos por parte de Administración podría estar amparado en diversos motivos de utilidad pública o interés social relacionados con la necesidad o conveniencia de intervención en el mercado inmobiliario. En consecuencia, no se estaría contraviniendo lo preceptuado en el artículo 103 de la Constitución, ni evidentemente se estaría ante ninguna expropiación, pues es el particular, propietario de la vivienda calificada como protegida, quien decide y quiere venderla y por cuya venta se le va a abonar el precio máximo estipulado normativamente. En suma, cuando la Administración opte por ejercitar estos derechos, pese a que tanto el comprador como el vendedor cumplan los requi-

\footnotetext{
${ }^{27}$ En este sentido José Ignacio MORILLO-VELARDE PÉREZ pone de relieve que los derechos de tanteo y retracto "no pueden ejercitarse de manera discrecional, sino vinculado a que la transmisión se efectúe o no a quien reúna los requisitos legales para acceder a dichos tipos de viviendas. Pero esta decisión es una decisión netamente administrativa que se materializa en un acto administrativo pleno revisable por los Tribunales de la jurisdicción contencioso-administrativa", vid. "Los Retractos Legales a favor de las Administraciones Públicas", ob. cit., pág. 69. En la misma línea, vid. Joaquín ZEJALBO MARTÍN, "Derechos de tanteo y retracto en la reciente Ley andaluza de la Vivienda Protegida", ob. cit., pág. 3 de 6, "La doctrina sobre la retroactividad y la aplicación inmediata de la Ley a propósito de la Ley andaluza sobre Vivienda Protegida y cuestiones prácticas", ob. cit., págs. 4 y 5 de 7 y "La retroactividad y la aplicación inmediata de la Ley andaluza de Vivienda Protegida", de marzo de 2006, en BOE para Notarías, Registros y Sociedades, en http://www.notariosyregistradores.com/doctrina/ARTICULOS, pág. 14 de 20.
} 
sitos descritos legalmente, habrá de motivarlo suficientemente [artículo 54.1.f) de la Ley 30/1992, de 26 de noviembre], no incurriéndose por ello en arbitrariedad alguna.

Y por último, en conexión con la situación planteada, podemos preguntarnos si puede el vendedor retractarse de su intención de vender la vivienda en el caso de que la Administración manifieste que va a ejercitar el derecho de tanteo.

Desde nuestro punto de vista, en principio, el propietario de una vivienda protegida que haya realizado las comunicaciones a que le obliga el artículo 12 de la Ley podría retractarse antes de que la Administración le conteste en el plazo de los sesenta días. Sin embargo, una vez que la Administración le manifieste su deseo de comprar la vivienda, ya no podría arrepentirse, dado que hay un acuerdo de voluntades. El particular manifestó por escrito su voluntad, su intención de vender la casa por ese precio. Una vez que la Administración le contesta y ejerce el derecho de tanteo existiría un acuerdo de voluntades conforme a lo dispuesto en los artículos 1254 y 1258 del Código Civil ${ }^{28}$.

\section{APLICACIÓN TEMPORAL DE LOS DERECHOS DE TANTEO Y RETRACTO LEGAL}

\section{A. Posibles interpretaciones sobre el grado de retroactividad de la Ley $13 / 2005$}

En cuanto a la aplicación de los derechos de tanteo y retracto legal a las viviendas calificadas como de protección oficial o protegidas con posterioridad a la entrada en vigor del Real Decreto-Ley 31/1978, de 31 de octubre, dado que la Ley no contempla ninguna Disposición Transitoria al respecto, pueden mantenerse distintas interpretaciones sobre su grado de retroactividad ${ }^{29}$.

\footnotetext{
${ }^{28}$ Dispone el art. 1254 del Código Civil que: "El contrato existe desde que una o varias personas consienten en obligarse, respecto de otra u otras, a dar alguna cosa o prestar algún servicio". Por su parte, el art. 1258 establece que: "Los contratos se perfeccionan por el mero consentimiento, y desde entonces obligan, no sólo al cumplimiento de lo expresamente pactado, sino también a todas las consecuencias que, según su naturaleza, sean conformes a la buena fe, al uso y a la ley”.

${ }^{29}$ Como pone de manifiesto Francisco LÓPEZ MENUDO, lo conveniente es que sea el propio legislador quien organice el cambio normativo mediante normas de transición, tanto para facilitar la tarea del intérprete como a efectos de autocontrol del propio legislador, vid. El principio de irretroactividad en las normas jurídico-administrativas, Ediciones del Instituto García Oviedo, núm. 51, Universidad de Sevilla, 1982, págs. 72-74.
} 
Tanto desde un punto de vista doctrinal como jurisprudencial, se suelen distinguir tres tipos de retroactividad: de grado o tipo máximo, que es aquella en la que la nueva Ley afecta no sólo a relaciones jurídicas nacidas sino también a las ya consumadas; de tipo medio, esto es, aquella en la que la nueva Ley respeta la relación jurídica básica pero somete a su vigencia los efectos nacidos antes de aquélla pero pendientes de ejecución; y la de grado mínimo, que es aquella en la que la nueva Ley resulta únicamente aplicable a los efectos nacidos tras su entrada en vigor ${ }^{30}$.

Atendiendo a lo dispuesto en el apartado tercero del artículo 2 del Código Civil ("Las leyes no tendrán efecto retroactivo si no dispusieren lo contrario"), una primera postura abogaría por la aplicación de cuantas prohibiciones y limitaciones a la facultad de disponer se regulan en la Ley 13/2005 exclusivamente a las viviendas que sean calificadas como protegidas con posterioridad a su entrada en vigor ${ }^{31}$.

Esta tesis encontraría también apoyo en el tenor literal del artículo 2 de la Ley 13/2005 que dispone que, a los efectos de la misma, se entiende por vivienda protegida la que cumpla determinadas condiciones y sea calificada como tal por la Consejería competente en materia de vivienda. ${ }^{32}$

${ }^{30}$ En relación con este tema Francisco LÓPEZ MENUDO comentaba que "La teoría del efecto inmediato de P. Roubier se ha asentado en el Tribunal Constitucional y se ha ido abriendo paso en el Tribunal Supremo. La Constitución deja fuera de la prohibición el gran tramo compuesto por los grados medio y mínimo. La retroacción blanda y no prohibida, ya no tiene de retroacción ni siquiera el nombre: se la intenta bautizar como retrospección para que así no se confunda en ningún caso con la retroacción que se considera verdadera. Cada vez más se utiliza el concepto de retroactividad propia e impropia. La verdadera es la primera", vid. "El principio de irretroactividad. Tres cuestiones claves”, Documentación Administrativa, núm. 263-264 (2002), págs. 73-105 y, más concretamente, las págs. 81-82.

31 En esta línea se sitúa Joaquín DELGADO RAMOS, vid. "Tanteo y retracto y prohibición de disponer en transmisiones intervivos de viviendas protegidas en Andalucía", actualizado a 13 de junio de 2006, en htpp://www.notariosyregistradores.com. De acuerdo con este autor: a quien compró antes de la Ley 13/2005 y vende tras ella, no se le aplica ni la prohibición de disponer ni los derechos de tanteo y retracto legal; a quien compre después de la Ley una vivienda calificada antes, tampoco le afecta la regulación legal, con la salvedad de que una Ley o un reglamento posterior matizaran la redacción de los arts. 12 y 13 de la Ley 13/2005, en cuyo caso sí les afectaría; y a quien compre después de la entrada en vigor de la Ley una vivienda calificada también después de la misma, se la aplican los arts. 12 y 13 de la citada Ley.

32 De acuerdo con la dicción de este precepto se han mantenido por algunos autores interpretaciones de signo totalmente diverso: la primera considera que no es de aplicación lo dispuesto 
No obstante el tenor literal del artículo 2 del Código Civil, la retroactividad prohibida por este precepto, de acuerdo con las disposiciones transitorias primera y cuarta del Código Civil, es la de grado máximo, o retroactividad plena.

Sobre este particular el Tribunal Supremo ${ }^{33}$ se ha posicionado en el sentido de entender que la inaplicación retroactiva de la norma se refiere a los efectos jurídicos producidos y ejecutados bajo la legislación anterior.

Por su parte, el Tribunal Constitucional ${ }^{34}$ ha declarado que "la prohibición de la retroactividad solo es aplicable a los derechos consolidados, asumidos e integrados en el patrimonio del sujeto, y no a los pendientes, futuros, condicionados, expectativas,...”. En la sentencia 182/1997, de 28 de octubre, el Tribunal Constitucional expuso que "la jurisprudencia constitucional ha diferenciado entre retroactividad auténtica o de grado máximo y la retroactividad impropia o de grado medio". De acuerdo con su doctrina “... no hay retroactividad cuando una Ley regula de manera diferente y pro futuro situaciones jurídicas creadas con anterioridad a su entrada en vigor y cuyos efectos no se han consumado, pues, (...), una norma es retroactiva, a los efectos del artículo 9.3 de la Constitución, cuando incide sobre "relaciones consagradas" y "afecta a situaciones agotadas" y lo que se prohíbe en el artículo 9.3 es la retroactividad entendida como una incidencia de la nueva Ley en los efectos jurídicos ya producidos de situaciones anteriores, de suerte que la incidencia en los derechos, en cuanto a su proyección en el futuro, no pertenece al campo estricto de la irretroactividad" (STC 227/1998).

en esta Ley a aquellas viviendas protegidas que hubieran sido calificadas como tales por la Administración del Estado, y no por la Administración autonómica andaluza, vid. Joaquín DELGADO RAMOS, "Aspectos notariales y registrales de la Ley (Andalucía) 13/2005, de 11 de noviembre, de medidas para la vivienda protegida y el suelo", en htpp://www.notariosyregistradores.com; en cambio, la segunda tesis aboga por no excluir del ámbito de aplicación de la Ley a aquellas viviendas calificadas como protegidas por el Estado, dado que la Comunidad Autónoma Andaluza se subrogó en la posición de éste, en materia de vivienda protegida, mediante el Decreto de Transferencia 3481/1983, de 28 de diciembre, vid. Joaquín ZEJALBO MARTÍN, "Derechos de tanteo y retracto en la reciente Ley andaluza de la Vivienda Protegida", ob. cit., pág. 4 de 6 y "La retroactividad y aplicación inmediata de la Ley andaluza de Vivienda Protegida”, ob. cit., págs. 6 y 7 de 20.

${ }^{33}$ Entre otras, vid. SSTS, Sala de lo Contencioso-administrativo, de 22 de junio de 1994 (RJ 1994 15092), 5 de febrero de 1996 (RJ 1996\1039), 15 de abril de 1997 (RJ 19973086), 4 de junio de 2001 (RJ 2002\3119) y 21 de abril de 2005 (RJ 200513476).

${ }^{34}$ Entre otras, vid. SSTC 42/1986, de 10 de abril, 99/1987, de 11 de junio, 227/1988, de 29 de noviembre, 210/1990, de 20 de diciembre, 182/1997, de 28 de octubre, 6/2004, de 16 de enero, $83 / 2005$, de 7 de abril y $230 / 2005$, de 26 de septiembre. 
Una segunda postura se basa en el tenor de la Disposición Adicional Tercera de la Ley 13/2005, que establece que las referencias que ésta contiene a la regulación "por los correspondientes planes de vivienda y suelo" se entenderán realizadas al actual Plan Andaluz de Vivienda y Suelo 2003-2007, o Plan que lo sustituya. De acuerdo con esta norma podría mantenerse la siguiente interpretación: que la presente Ley es de aplicación a todas las viviendas que sean calificadas de conformidad con el citado Plan Andaluz para el cuatrienio 2003-2007, a pesar de que dicha calificación fuera anterior al 12 de diciembre de $2005^{35}$.

Por último, hay otra posible interpretación consistente en entender que la Ley carece de efectos retroactivos puesto que los derechos de tanteo y retracto legal los ejercerá la Administración de la Junta de Andalucía sobre todas aquellas segundas o ulteriores transmisiones de viviendas calificadas como protegidas que se produzcan tras su entrada en vigor no afectando, por tanto, al régimen jurídico de las mismas ${ }^{36}$.

Pues bien, desde nuestro punto de vista, este último razonamiento jurídico es el que ha realizado el legislador andaluz y, de acuerdo con el mismo, hay que concluir que la Ley 13/2005, por lo que hace al ejercicio de los derechos de tanteo y retracto, adolecería de una retroactividad de grado mínimo, puesto que sólo tiene efectos pro futuro, aunque la relación o situación jurídica haya surgido conforme a la normativa anterior y, por tanto, de acuerdo con la jurisprudencia del Tribunal Supremo y del Tribunal Constitucional no nos encontraríamos ante una retroactividad en sentido propio ${ }^{37}$.

${ }^{35}$ Esta postura es apuntada por Joaquín DELGADO RAMOS, no obstante, considera más sólida la interpretación de que la Ley únicamente deba de aplicarse a las viviendas calificadas como protegidas con posterioridad a la entrada en vigor de la Ley 13/2005, vid. "Aspectos notariales y registrales de la Ley (Andalucía) 13/2005, de 11 de noviembre, de medidas para la vivienda protegida y el suelo", en htpp://www.notariosyregistradores.com.

${ }^{36}$ De acuerdo con la opinión de Joaquín ZEJALBO MARTÍN, consideramos que "no existe en el propietario de vivienda protegida un derecho adquirido a transmitir mediante compraventa dicha vivienda sin un derecho de tanteo y retracto preventivo del fraude inmobiliario... El legislador le faculta para vender por el precio máximo y demás requisitos pero nada más, todo lo que exceda de lo anterior puede estar sometido a tanteo y retracto". Vid. "La doctrina sobre la retroactividad y la aplicación inmediata de la Ley a propósito de la Ley andaluza sobre Vivienda Protegida y cuestiones prácticas", ob. cit. pág. 4 de 7 . Y sobre el concepto de derecho adquirido vid. Concepción BARRERO RODRÍGUEZ, "El respeto a los derechos adquiridos", Documentación Administrativa núm. 263 (2002), págs. 137-183.

${ }^{37}$ En este sentido, Joaquín ZEJALBO MARTÍN trae a colación la Resolución de la Dirección General de los Registros y del Notariado de 5 de octubre de 2005 (BOE de 18 de noviembre de 


\section{B. Normativa dictada en desarrollo de los artículos 12 y 13 de la Ley 13/2005}

Partiendo de la base de que los derechos de tanteo y retracto no son jurídicamente de obligado ejercicio para la Administración, ésta podrá valorar su no aplicación durante un determinado ámbito temporal por razones de política económica o social ${ }^{38}$. Por ello, y probablemente con el fin de evitar el ejercicio de los referidos derechos sobre viviendas calificadas como protegidas hace un periodo de tiempo excesivamente largo, se ha procedido a regular a través de las siguientes normas su aplicación temporal.

a) Instrucción de 29 de diciembre de 2005, de la Dirección General de Arquitectura y Vivienda, relativa a las segundas y posteriores transmisiones de las viviendas de protección oficial acogidas a regímenes anteriores al Real Decreto-Ley 31/1978, de 31 de octubre (BOJA núm. 5, de 10 de enero de 2006).

De acuerdo con el título de la propia Instrucción, la misma se refiere a las segundas y posteriores transmisiones de viviendas acogidas a regímenes anteriores al Real Decreto-Ley 31/1978. En concreto, la Instrucción se dirige a las viviendas sujetas al Real Decreto 2960/1976, de 12 de noviembre, por el que se aprueba el Texto Refundido de Vivienda de Protección Oficial y al Decreto 2114/1968, de 24 de julio, por el que se aprueba el Reglamento para la aplicación de la Ley de Vivienda de Protección Oficial.

El periodo de protección de estas viviendas es de cincuenta años, por lo tanto, en la actualidad, mantienen su calificación como viviendas protegi-

2005), en la que se aborda, con respecto a la normativa gallega, un problema similar al planteado con la Ley andaluza. En dicha Resolución se reconoce que con la nueva normativa no se agrava un ápice la situación de los titulares de la vivienda enajenada puesto que "los derechos de tanteo y retracto no privan de la facultad de disposición, ni imponen el cumplimiento de otras condiciones de las ya establecidas". De acuerdo con este autor, los derechos de tanteo y retracto lo que suponen realmente es "un control de la regularidad de las transmisiones de viviendas protegidas, por ello es aplicable a todas las transmisiones de viviendas cualquiera que sea la fecha de la calificación como vivienda protegida, y ello no supone lógicamente una aplicación retroactiva de la Ley Andaluza sino un medio de garantizar realmente la aplicación de la legislación de las viviendas protegidas". Vid. "Derechos de tanteo y retracto en la reciente Ley andaluza de la Vivienda Protegida", en BOE para Notarías, Registros y Sociedades, http://www.notariosyregistradores.com/doctrina/ARTICULOS, págs. 2 y 3 de 6.

${ }^{38}$ En este sentido, vid. Joaquín ZEJALBO MARTÍN, "Derechos de tanteo y retracto en la reciente Ley andaluza de la Vivienda Protegida", ob. cit., pág. 5 de 6. 
das ${ }^{39}$. No obstante, tal y como expone la propia Instrucción de 29 de diciembre de 2005, dado que el Real Decreto 727/1993, de 14 de mayo, modificó el régimen de protección de las viviendas de protección oficial acogidas a regímenes anteriores al Real Decreto-Ley 31/1978 en el sentido de que para las segundas y posteriores transmisiones el precio de estas viviendas sería el de mercado, pese a mantener su calificación de protegidas, resulta inaplicable en estos casos el nuevo régimen legal descrito en los artículos 12 y siguientes de la Ley 13/2005, de 11 de noviembre.

En efecto, al no estar sujetas las segundas y ulteriores transmisiones de estas viviendas a precio máximo, lo dispuesto en el apartado 6 del artículo 12 de la Ley en relación con que el derecho de tanteo se ejercerá hasta por un precio máximo igual al vigente para las viviendas protegidas de la tipología de que se trate en el correspondiente ámbito territorial en la fecha en la que se pretenda la enajenación, así como que el derecho de retracto se ejercerá por el precio de transmisión, que no podrá superar el vigente para las viviendas protegidas a las que se acaba de hacer alusión, se antoja carente de sentido ${ }^{40}$.

b) Orden de 20 de enero de 2006, relativa al ejercicio de los derechos de tanteo y retracto legal en las segundas o posteriores transmisiones de viviendas calificadas como protegidas con anterioridad a la entrada en vigor de la Ley 13/2005, de 11 de noviembre, de Medidas para la Vivienda Protegida y el Suelo.

De acuerdo con lo dispuesto en la Orden de 20 de enero de 2006 (publicada en el BOJA número 16, de 25 de enero de 2006), el ejercicio de los citados derechos por parte de la Administración de la Junta de Andalucía irá en función de cuál sea el Plan de Vivienda y Suelo al amparo del que se calificó la vivienda.

\footnotetext{
${ }^{39}$ Con anterioridad a este grupo de viviendas, los periodos de protección de las viviendas acogidas, por una parte, a la Ley de 19 de abril de 1939 y al Reglamento de 8 de septiembre de 1939 y, por otra, a la Ley 15 de julio de 1954, vivienda de renta limitada y al Reglamento de 24 de junio de 1955, vivienda de renta limitada, era de veinte años, con lo cual, en la actualidad todas las viviendas acogidas a estos regímenes son libres.

${ }^{40}$ En este sentido también se manifiesta Joaquín ZEJALBO MARTÍN al destacar que al ser libre el precio de estas viviendas "es imposible cumplir la función social expuesta de dichos derechos, aparte de ser imposible también la aplicación de la nueva Ley al ejercitarse dichos derechos de tanteo y retracto por un precio máximo, que en este caso no existe al ser libre", vid. "Derechos de tanteo y retracto en la reciente Ley andaluza de la Vivienda Protegida", de 19 de diciembre de 2005, en BOE para Notarías, Registros y Sociedades, en http://www.notariosyregistradores.com/doctrina/ARTICULOS, pág. 3 de 6.
} 
1. Del texto de la Orden se desprende, en primer lugar, respecto de las segundas y posteriores transmisiones de las viviendas calificadas de conformidad con el Real Decreto-Ley 31/1978 y Planes sucesivos anteriores al I Plan andaluz de Vivienda y Suelo, aprobado por el Decreto 119/1992, de 7 de julio, que la Consejería de Obras Públicas y Transportes no ejercerá los derechos de tanteo y retracto legal. No obstante, les será exigible la realización del régimen de comunicaciones previsto en el artículo 12 de la Ley, lo que conlleva que las transmisiones de dichas viviendas habrán de ajustarse a los requisitos de precio máximo ${ }^{41}$ y a las condiciones exigidas por los correspondientes programas de protección a los adquirentes de vivienda protegida, esto es, no superar unos determinados ingresos económicos ${ }^{42}$, destinar la vivienda a residencia habitual y permanente y no ser titular ni estar en posesión de ninguna otra vivienda protegida o libre, de acuerdo con lo dispuesto en los artículos 4 de la Ley 13/2005 y 5.1 de la propia Orden.

Aunque la Orden no establece expresamente que sobre estas viviendas vayan a ejercitarse los derechos de tanteo o retracto legal, se colige que si han de cumplir con el régimen de comunicaciones y los requisitos relativos al límite de precio de venta y de tipo económico con respecto al comprador, en el caso de que no se respeten los mismos la Administración podría ejercitar el derecho de retracto. No obstante, dada la antigüedad de estas viviendas, sería improbable que ello sucediese puesto que lo lógico es que quien pretenda venderla solicite la descalificación de la misma, de acuerdo con lo dispuesto en la Disposición Transitoria Segunda del Decreto 149/2006, de 25 de julio, que regula expresamente las "Descalificaciones de Viviendas Protegidas, adquiridas, adjudicadas o construidas para uso propio con anterioridad a este Decreto".

\footnotetext{
${ }^{41}$ Vid. el Anexo 2 de la Orden de 20 de enero de 2006 en el que se contiene la tabla de precios máximos, distinguiendo entre la vivienda usada para su tenencia en régimen de propiedad y la vivienda de régimen especial en venta. Los precios resultantes de aplicar las cantidades fijadas en dicha tabla, habrán de incrementarse en función de la antigüedad de la vivienda, respecto de su calificación definitiva, aplicando los coeficientes establecidos en el artículo 94 del Texto Integrado del Decreto 149/2003, de 10 de junio. Por su parte, la valoración máxima de los garajes y trasteros vinculados a las viviendas no podrá superar el $60 \%$ de los precios establecidos en esta Tabla, de acuerdo con el art. 59.3 del citado Texto Integrado, que se remite a lo dispuesto en el apartado 1 del artículo 31 del Real Decreto 801/2005, de 1 de julio.

42 Vid. el Anexo 1 de la Orden de 20 de enero de 2006 en el que se contiene la tabla de equivalencias de las viviendas protegidas a los efectos de los ingresos familiares.
} 
2. En segundo lugar, en cuanto a las viviendas procedentes del I Plan Andaluz de Vivienda y Suelo 1992-1995 y del II Plan Andaluz de Vivienda y Suelo 1996-1999, aprobados por los Decretos 119/1992, de 7 de julio, y 51/1996, de 6 de febrero, respectivamente, les será de aplicación el régimen de las comunicaciones previsto en la Ley, estando la Administración obligada a ejercer el derecho de retracto legal cuando la transmisión se haya efectuado incumpliendo los requisitos de precio máximo y condiciones del adquirente.

3. Y por último, con relación a las transmisiones de viviendas acogidas al III Plan andaluz de Vivienda y Suelo para 1999-2002 y al IV Plan Andaluz de Vivienda y Suelo para el 2003-2007, aprobados por los Decretos 166/1999, de 27 de julio y 149/2003, de 10 de junio, respectivamente, éstas deberán ajustarse al régimen establecido en los artículos 12 y 13 de la Ley, y sobre las mismas la Consejería de Obras Públicas y Transportes ejercitará los derechos de tanteo y retracto legal.

En este contexto, hay que señalar que el artículo 4 de la Orden de 20 de enero de 2006 establece unas excepciones al ejercicio de los referidos derechos, en concreto: cuando la transmisión tenga lugar entre parientes hasta el segundo grado de consanguinidad; y cuando se trate de la transmisión de una cuota indivisa de la vivienda a favor de otra persona titular de ésta.

c) Orden de 10 de marzo de 2006, de desarrollo y tramitación de las actuaciones en materia de vivienda y suelo del Plan Andaluz de Vivienda y Suelo 2003-2007 (BOJA núm. 66, de 6 de abril).

En concreto, esta Orden dedica el artículo 47 al ejercicio del derecho de tanteo y retracto. La única novedad que viene a presentar con respecto a las normas ya publicadas es la incorporación de la relación de documentos que debe presentar la persona interesada en la adquisición de la vivienda. En este sentido, nos remitimos a lo dicho en la letra $\mathrm{E}$ del epígrafe II, relativa al régimen de las comunicaciones.

d) Decreto 149/2006, de 25 de julio de 2006 .

El Reglamento de Viviendas Protegidas en la Comunidad Autónoma de Andalucía aprobado por el Decreto 149/2006, de 25 de julio (BOJA núm. 153, de 8 de agosto), dedica el Capítulo II a los derechos de tanteo y retracto legal, artículos 50 a 54 . Algunas de las novedades o precisiones que incorpora este Decreto respecto a la regulación ya existente han ido comentándose en anteriores apartados. No obstante, restan por resaltar algunas otras, tales como: 
Por una parte, el apartado tercero del artículo 50 asimila a la excepción al ejercicio de los derechos de tanteo y retracto que contempla el artículo 4 de la Orden de 20 de enero de 2006, relativa a la transmisión de una cuota indivisa de la vivienda a favor de otra persona titular de la misma, los casos de particiones de herencia y disoluciones de condominio y de sociedades conyugales, cuando uno de los cotitulares adquiera la totalidad de la vivienda abonando en metálico la parte de los demás condueños.

Y por otra, el artículo 54 regula la posibilidad de la Consejería, o de la Empresa Pública o el Ayuntamiento al que se le haya cedido el ejercicio de los derechos de tanteo y retrato, para designar a una persona que reúna los requisitos para ser titular de una vivienda protegida para que se subrogue en su lugar en el acto de adquisición, hecho éste que se deberá acreditar al Notario. Asimismo, habrá de incorporarse a la escritura testimonio de la resolución en la que conste tal designación.

En el caso de que no se haya realizado la subrogación arriba comentada, se contempla la posibilidad de que la Administración o Entidad Pública adquirente de la vivienda protegida solicite de la correspondiente Delegación Provincial el cambio de régimen de protección de la vivienda. Si se autoriza dicho cambio, la resolución deberá fijar una nueva calificación definitiva de la vivienda, que habrá de reflejarse registralmente, e indicar las consecuencias que resulten del cambio de programa.

\section{ESPECIAL REFERENCIA A LA PROHIBICIÓN DE TRANSMI- SIÓN O CESIÓN DE USO DE LA VIVIENDA EN LAS SEGUNDAS O POSTERIORES TRANSMISIONES}

A partir de 1998, los Reales Decretos y Decretos reguladores de la materia de vivienda protegida han establecido una prohibición de disponer sobre la vivienda durante el plazo de cinco o de diez años desde la calificación definitiva. Así, de acuerdo con los artículos 27 y 95 de la Orden de 8 de agosto de 2005 por la que se publica el Texto Integrado del Decreto 149/2003 los adquirentes, adjudicatarios y promotores individuales para uso propio de viviendas protegidas, no podrán transmitir ni ceder el uso de las mismas durante el plazo de diez años, salvo que se den alguna de las situaciones contempladas en el art. 13.5 del Real Decreto $801 / 2005$, de 1 de julio ${ }^{43}$, o por

\footnotetext{
${ }^{43}$ En concreto, el art. 13.5 del Real Decreto 801/2005 se refiere a los supuestos de aumento del número de miembros de la unidad familiar, personas mayores de 65 años, personas discapacitadas, víctimas de la violencia de género, víctimas de terrorismo y a otros casos de personas que por circunstancias personales justificadas deseen cambiar su domicilio a una vivienda de menores dimensiones.
} 
cambio de localidad de residencia del titular de la vivienda, por subasta y adjudicación de la vivienda, por ejecución judicial del préstamo o por otros motivos justificados, siempre que se obtenga autorización de la correspondiente Delegación Provincial de la Consejería de Obras Públicas y Transportes ${ }^{44}$.

En esta línea ha de interpretarse el párrafo segundo del apartado primero del artículo 12 de la Ley cuando establece que el adquirente de una vivienda protegida en segunda o posterior transmisión no podrá venderla, como mínimo, en los diez años siguientes a que se produzca aquélla.

De acuerdo con la redacción inicial dada por la Ley 13/2005 al párrafo segundo del artículo 12.1, podían mantenerse diversas interpretaciones en torno a esta nueva limitación, así: en primer lugar, de acuerdo con una lectura ad pedem literae, no se contemplaba que fuera posible autorizar la venta de la vivienda antes de que transcurran diez años desde la segunda o posterior transmisión por ningún motivo; y en segundo lugar, de acuerdo con una interpretación lógica y sistemática con la normativa contenida en los Planes de Vivienda tanto estatal como andaluz, los mismos supuestos en los que excepcionalmente podía la Consejería autorizar la venta en los diez primeros años desde la primera adquisición de la vivienda, también serían aplicables a las segundas o posteriores transmisiones de viviendas que tuviesen lugar antes de transcurridos diez años ${ }^{45}$.

Esta segunda tesis vino a corroborarse con la aprobación de la enmienda transaccional al Anteproyecto de Ley de Modificación de la Ley $13 / 2005^{46}$ por

${ }^{44}$ Las autorizaciones de venta y, en concreto, la documentación que ha de presentarse junto a la solicitud de autorización, se detalla en el artículo 46 de la Orden de 10 de marzo de 2006.

${ }^{45}$ Hay que tener en cuenta que esta limitación se introdujo en sede parlamentaria, al ser aceptada una enmienda que proponía acomodar el texto de la Ley a lo recogido en el artículo 13.2 del Real Decreto 801/2005, de 1 de julio, por el que se aprueba el Plan Estatal 2005-2008, para favorecer el acceso de los ciudadanos a la vivienda. Pues bien, dicho artículo 13, en los apartados 3, 4 y 5 recoge un listado de supuestos en los que se puede dejar sin efecto dicha prohibición.

46 Sobre la proposición de esta enmienda en la sesión plenaria número 46, celebrada el 3 de mayo de 2006, a la Proposición de Ley 7-5/PPL-000004, relativa a la modificación de la Ley 13/2005, presentada por el Grupo Parlamentario Socialista, tramitada por el procedimiento de urgencia, vid. el Diario de Sesiones del Parlamento de Andalucía número 82, VII Legislatura, Año 2006, págs. 5413-5422 y el Boletín del Parlamento de Andalucía núm. 434, de 10 de mayo de 2006, págs. 24444 y 24445. 
la que se acuerda incluir al final del párrafo segundo del apartado primero del artículo 12 de la Ley lo siguiente: "con las excepciones que reglamentariamente se establezcan".

Dicho texto se recoge en la reciente Ley $1 / 2006$, de 16 mayo, de modificación de la Ley 7/2002, de 17 de diciembre, de Ordenación Urbanística de Andalucía, de la Ley 1/1996, de 10 de enero, de Comercio Interior de Andalucía, y de la Ley 13/2005, de 11 de noviembre, de Medidas para la Vivienda Protegida y el Suelo (BOJA núm. 98, de 24 de mayo de 2006).

Por lo tanto, aunque no hayan transcurrido diez años desde que se haya producido la segunda o posterior transmisión, cuando se alegue y pruebe que se da alguna de las circunstancias que se establecen en el artículo 26.2 del Reglamento de Vivienda Protegida, aprobado por el Decreto 149/2006, de 25 de julio, la Administración podrá autorizar dicha transmisión ${ }^{47}$.

\footnotetext{
${ }^{47}$ Dice el apartado segundo del artículo 26 del Reglamento de Vivienda Protegida:

"2. Respecto del requisito del tiempo, las personas titulares de una vivienda protegida no podrán transmitirla intervivos ni ceder su uso por ningún título, durante el plazo mínimo de diez años, salvo que el programa prevea un plazo inferior. Tal plazo empezará a contarse desde la fecha del otorgamiento de la correspondiente escritura pública o, en el supuesto de promotores individuales para uso propio, desde la fecha de la calificación definitiva.

Asimismo se podrán exceptuar de lo dispuesto en el párrafo anterior, por resolución motivada de la persona titular de la correspondiente Delegación Provincial de la Consejería competente en materia de vivienda, las transmisiones que tengan lugar por alguna de las causas siguientes:

a) Motivos laborales.

b) Incremento de los miembros de la unidad familiar.

c) Necesidad en un miembro de la unidad familiar mayor de 65 años.

d) Ser algún miembro de la unidad familiar víctima del terrorismo.

e) Ser algún miembro de la unidad familiar víctima de la violencia de género.

f) Otras situaciones sobrevenidas con incidencia en la unidad familiar, como son, entre otras, el fallecimiento o la discapacidad de alguno de sus miembros, o la nulidad, el divorcio o separación matrimonial o de uniones de hecho inscritas en el Registro de Parejas de Hecho.

g) Tratarse de la transmisión de una cuota indivisa de la vivienda a favor de quien ya fuese cotitular de ésta. Se entenderán comprendidos en este último supuesto las particiones de herencia y disoluciones de condominio y de sociedades conyugales, cuando una de las personas cotitulares adquiera la totalidad de la vivienda abonando en metálico el valor de la parte de las demás condueñas.

h) Otras que establezca el correspondiente plan de vivienda".
} 
Y finalmente, con respecto a la aplicación temporal de esta prohibición de disponer hay que decir que, al tratarse de un supuesto de retroactividad de grado máximo o propia se encuentra prohibida por nuestro ordenamiento, no resultando aplicable a las viviendas calificadas con anterioridad a la entrada en vigor de la Ley 13/2005.

\section{VALORACIÓN}

En conjunto, la regulación que de los derechos de tanteo y retracto ha acometido la Ley 13/2005 puede valorarse positivamente. Ciertamente, hay que reconocer que lo deseable hubiera sido que el legislador andaluz expresamente hubiese concretado los efectos retroactivos o no de la norma; no obstante, este déficit ha sido cubierto en parte con las Órdenes, Instrucciones y, finalmente, el Reglamento de Vivienda Protegida que al respecto ha dictado la Administración de la Junta de Andalucía.

En este contexto hay que resaltar, además, el hecho de que las limitaciones a la facultad de disponer que se recogen en el artículo 12 de la Ley 13/2005 ya existían con anterioridad en los correspondientes Planes de Vivienda y Suelo, con la salvedad de la relativa a la prohibición de venta en los diez años siguientes a la segunda o ulterior transmisión. La Ley 13/2005 lo único que ha hecho es elevar el rango de la regulación, completar el procedimiento y dotar a la Administración de una serie de mecanismos que le posibiliten hacer cumplir los fines descritos en la norma.

En suma, con estas medidas se ha dado un paso más en la lucha contra el fraude en materia de vivienda y contra la especulación del mercado inmobiliario, con mayor razón, del de la vivienda protegida que, no olvidemos, tiene una función social que cumplir que, evidentemente, no es enriquecer al que en su momento fue beneficiario de la misma, sino proporcionar una vivienda digna y adecuada a un sector de la sociedad con ingresos económicos insuficientes para acceder a una vivienda en el mercado libre. 